1 SUPPORTING INFORMATION to "Field calibrations of a

2 low-cost aerosol sensor at a regulatory monitoring site in

3 California"

4

5 D. M. Holstius ${ }^{1}$, A. Pillarisetti ${ }^{1}$, K. R. Smith ${ }^{1}$, and E. Seto ${ }^{2}$

$6[1]\{$ University of California, Berkeley, USA

7 [2] \{University of Washington, Seattle, USA

8 Correspondence to: D. M. Holstius (david.holstius@berkeley.edu)

9 

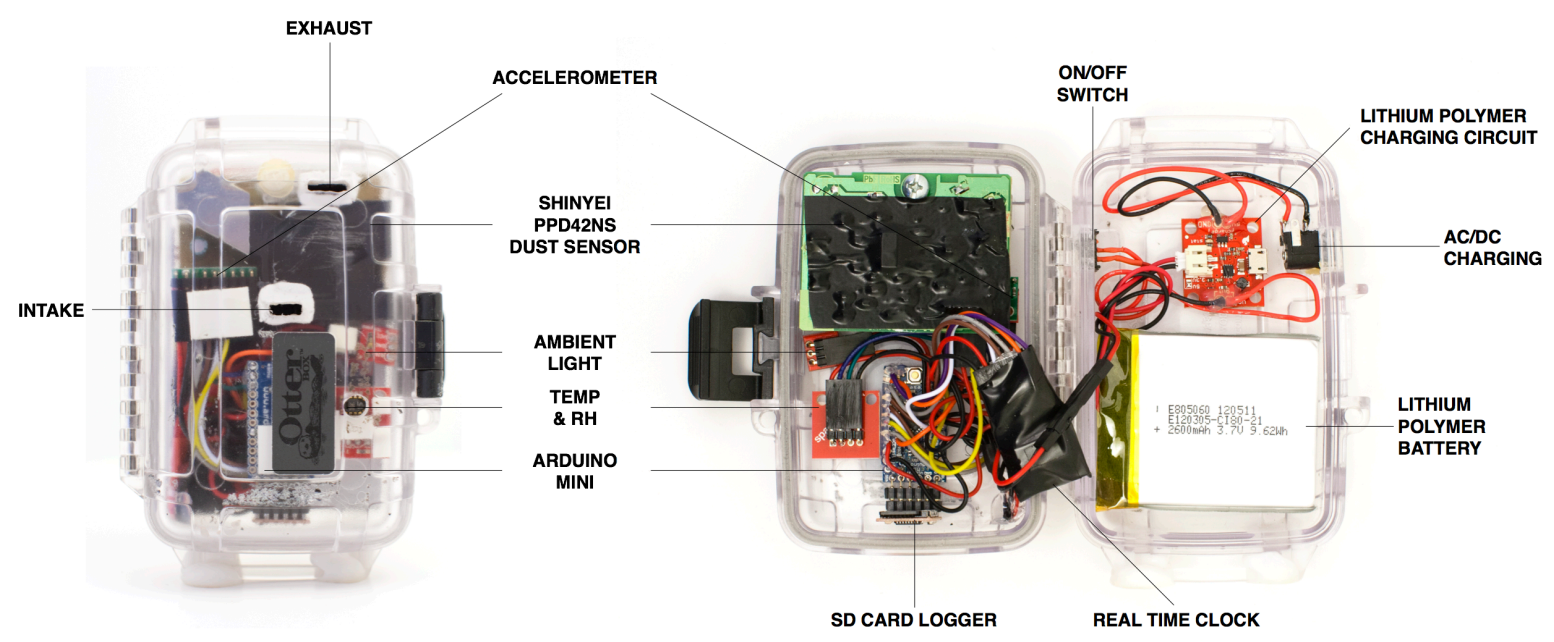

3 Figure S1. Elements and design of a PANDA instrument. All components were housed in a $412 \times 9 \times 4 \mathrm{~cm}, 250 \mathrm{~g}$ polycarbonate case, along with a charging circuit and a 16-hour, 2600 5 mAh lithium-polymer battery, which was charged continuously from a USB cable supplying $65 \mathrm{~V}$ power. Manufacturer part identifiers and approximate costs for all components are listed 7 in Table S1, Supporting Information. 


\begin{tabular}{|c|c|c|c|}
\hline & Component & Function & Approx Cost (\$) \\
\hline \multirow{7}{*}{ 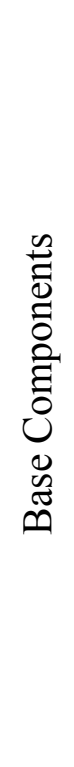 } & Arduino Pro Mini & Microcontroller & 10 \\
\hline & DS3234 & Real-time clock & 20 \\
\hline & Sparkfun OpenLog & MicroSD datalogger & 25 \\
\hline & Shinyei PPD42NS & Dust sensor & 16 \\
\hline & 2000-2600 mAh battery & Power system & 25 \\
\hline & Charging circuitry & Power system & 20 \\
\hline & OtterBox & Enclosure & 10 \\
\hline \multirow{3}{*}{ 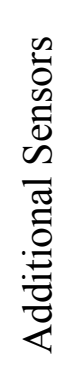 } & SHT15 / SHT75 & Temperature and $\mathrm{RH}$ & 40 \\
\hline & TEMT6000 & Ambient light sensor & 5 \\
\hline & ADXL335 & 3 -axis accelerometer & 25 \\
\hline
\end{tabular}

Total Cost of Materials: about $\$ 200.00$

1

2 Table S1. PANDA components. Prices indicative of June 2013 from popular online

3 electronics retailers, including SparkFun, AdaFruit, and SEEEDStudio, excluding taxes and

$4 \quad$ shipping.

5 

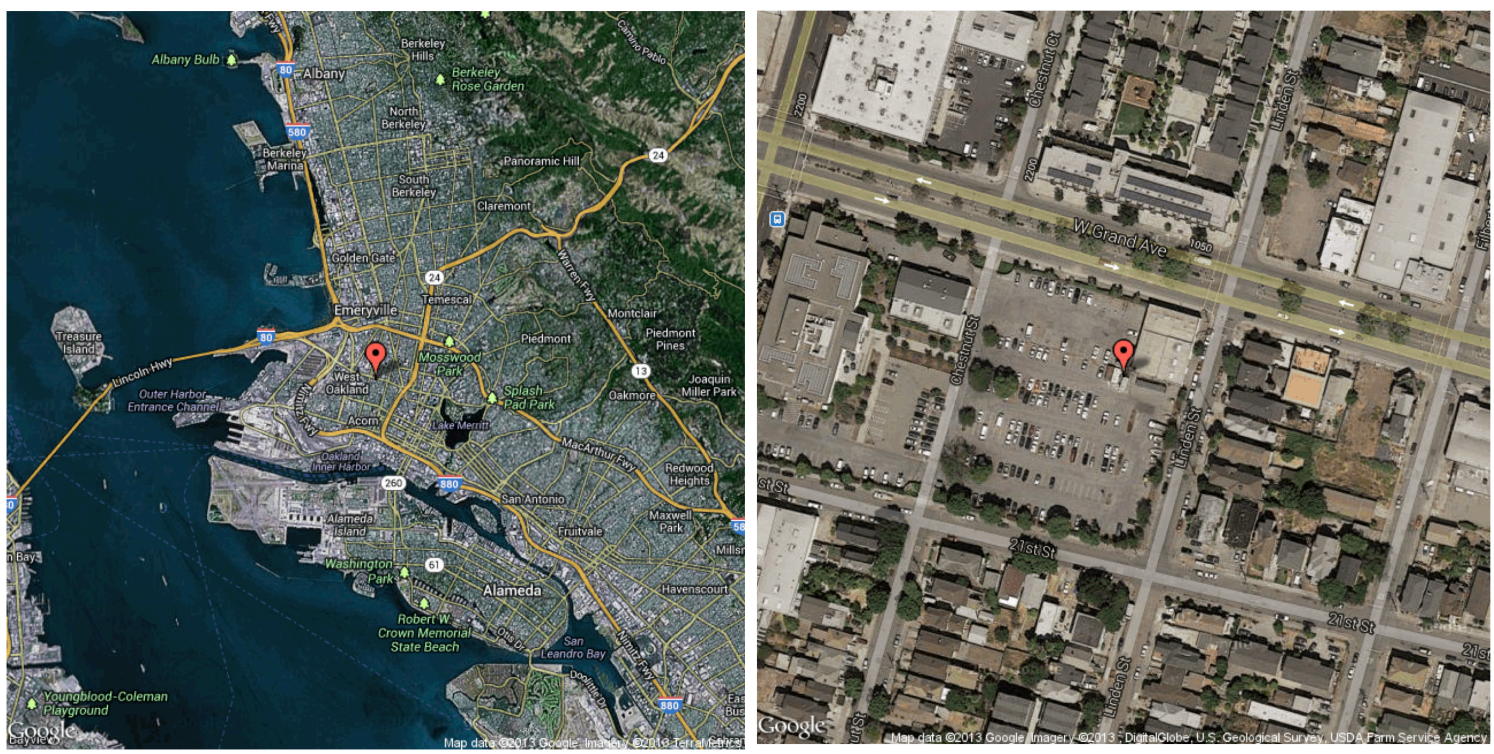

2 Figure S2. Location of the West Oakland monitoring site. Equipment was mounted on top of

3 the trailer operated by the Air District in a parking lot, approximately $5 \mathrm{~m}$ above ground level. 


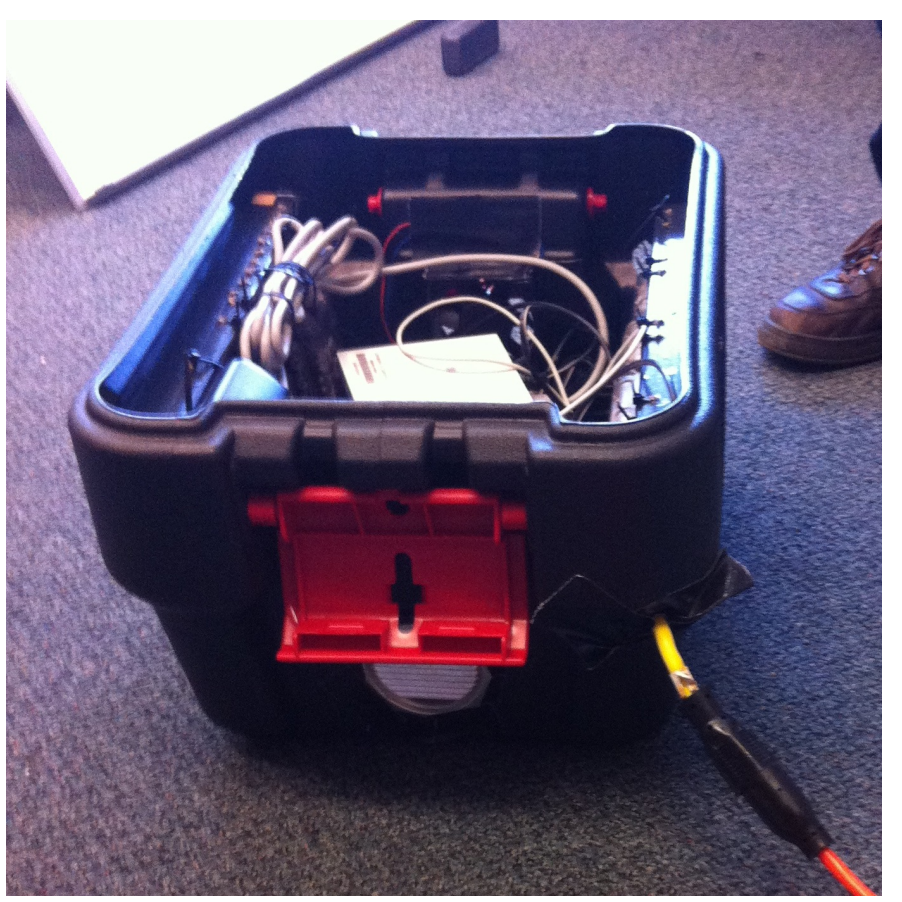

2 Figure S3. To house our instruments, we constructed a portable chamber from an 8-gallon 3 (30 L) plastic container, with $10 \mathrm{~cm}$ diameter holes cut into the front and rear. A $10 \mathrm{~cm} 12 \mathrm{~V}$ 4 DC fan (Radio Shack \#273-243, 33 CFM) flush with the rear (exhaust) vent served to draw 5 in ambient air. Using zip-ties, we secured PANDAs, a Dylos ${ }^{\mathrm{TM}}$ DC1700, a GRIMM v1.108, 6 and a laptop inside the chamber, along with AC power supplies. Due to space limitations, we 7 constructed a second chamber to house our DustTrak ${ }^{\mathrm{TM}}$ II Aerosol Monitor. We ran 1/4 inch 8 tubing from the first chamber to the DustTrak, which has an active inlet and a $2.5 \mu \mathrm{m}$ 9 impactor. We ran $120 \mathrm{~V}$ AC power from an outlet on the Air District trailer to a surge 10 protector in each chamber and placed both chambers on the trailer roof from Apr 15-23 2013. 


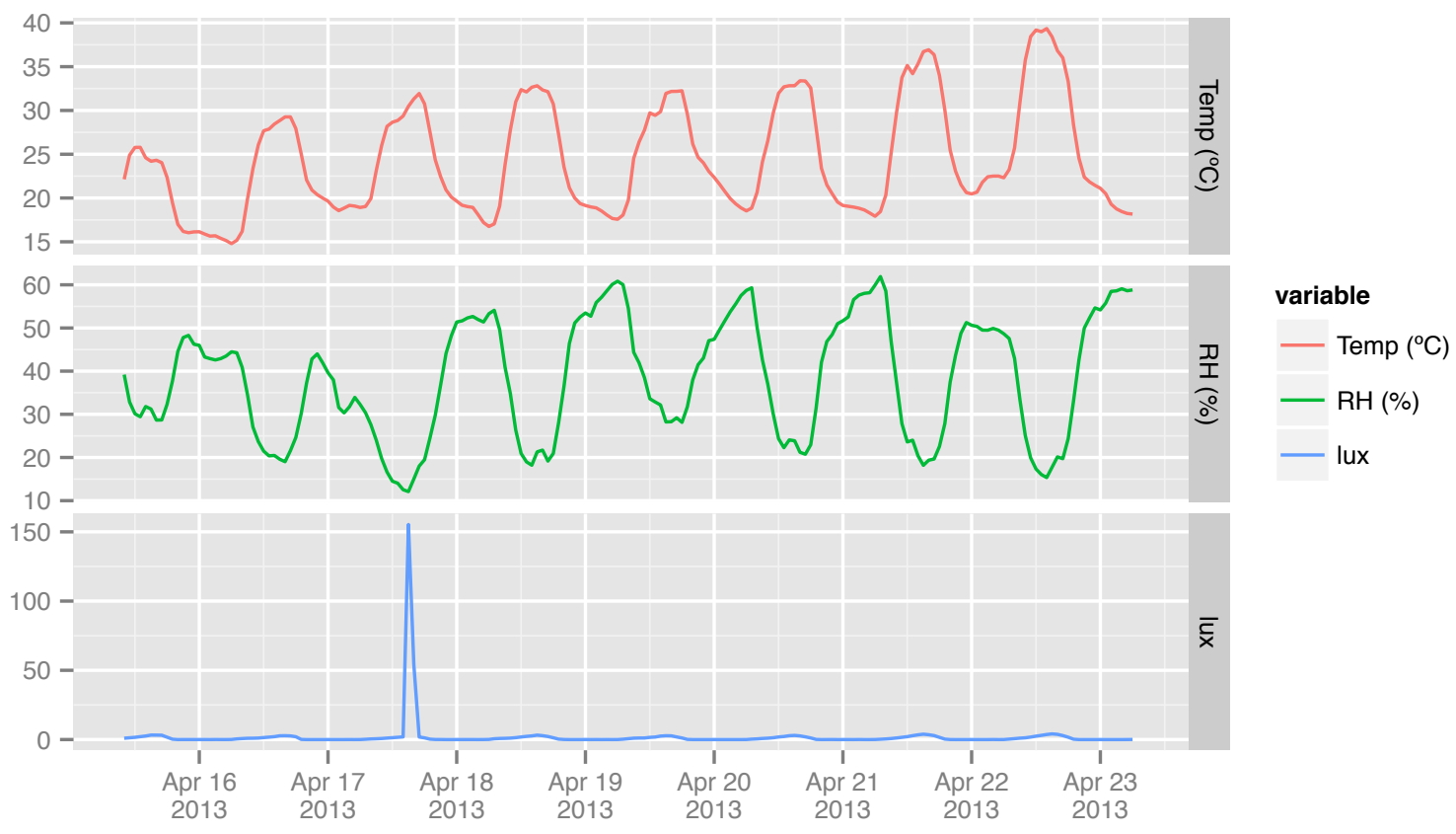

1

2 Figure S4. Relative humidity varied between 20 and $60 \%$. Temperature was elevated relative 3 to ambient temperature, presumably due to heat generated by the electronics. Ambient light 4 was consistent across the study, save during the $1 \mathrm{~h}$ spot check when the lid of the chamber 5 was removed to evaluate the operational status of equipment. 


\section{Pilot Study}

2 As a pilot study, we colocated 5 Shinyei PPD42NS sensors in a $70 \mathrm{~m}^{3}$ office environment,

3 located on the $5^{\text {th }}$ floor of a building in downtown Berkeley, CA, for 6 weeks (Jul 16-Aug 30

4 2012). All windows were left open to promote extensive infiltration of outside air. Our aims

5 for the pilot study were: (a) to assess whether previously reported high-frequency (1-minute)

6 correlations between a PPD42NS and a consumer-grade optical counter (OPC) could be

7 reproduced with a longer integration time (1 hour) at the much lower concentrations

8 characteristic of ambient urban aerosol; and (b) to assess variations in response among a

9 sample of PPD42NS sensors. We collected 1-minute data from a consumer-grade OPC (Dylos

10 DC1700) positioned within $30 \mathrm{~cm}$ of the sensors. All data were subsequently binned and

11 analyzed using $1 \mathrm{~h}$ arithmetic means.

12 During our pilot study, we observed very high pairwise correlations $\left(\mathrm{R}^{2}\right)$ of $0.98-0.99$ 13 between all sensors (Figure S6). The data were left-skewed, with $99 \%$ of observations 14 between 0.013-1.623 and 95\% between 0.023-1.362 (\% FS; see Methods for an explanation 15 of the metric). The mean and median were 0.366 and $0.215 \%$ FS, respectively. The overall 16 correlation between PANDAs and the OPC was slightly lower but still high, with $\mathrm{R}^{2}=0.85-$ 17 0.87. We did not observe any obvious signs of an upper or lower detection limit in either 18 PANDAs or OPC data. 


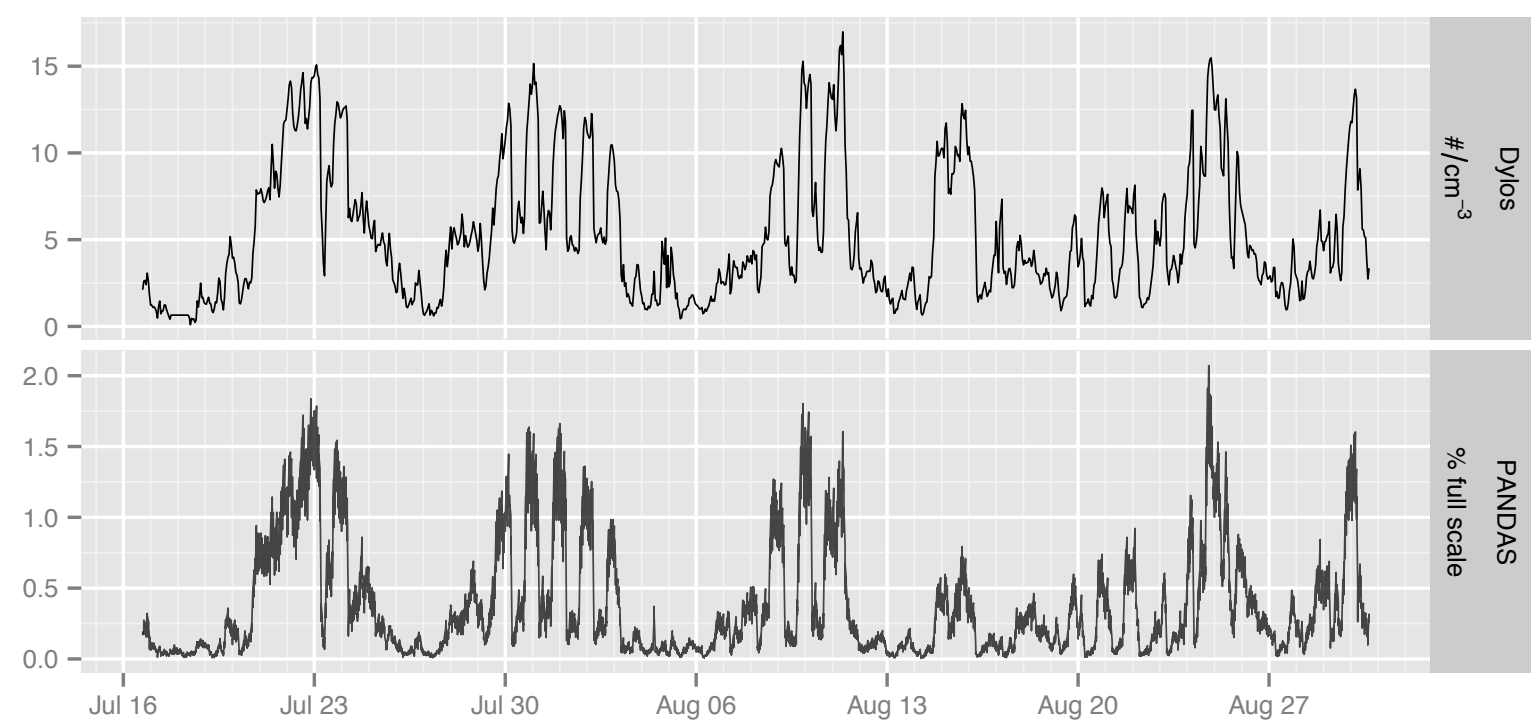

1

2 Figure S5. Temporal patterns (pilot study). Top: number concentration $\left(0.3<d_{p}<2.5 \mu \mathrm{m}\right)$

3 from optical particle counter (Dylos DC1700). Bottom: 5 colocated PPD42NS sensors. 


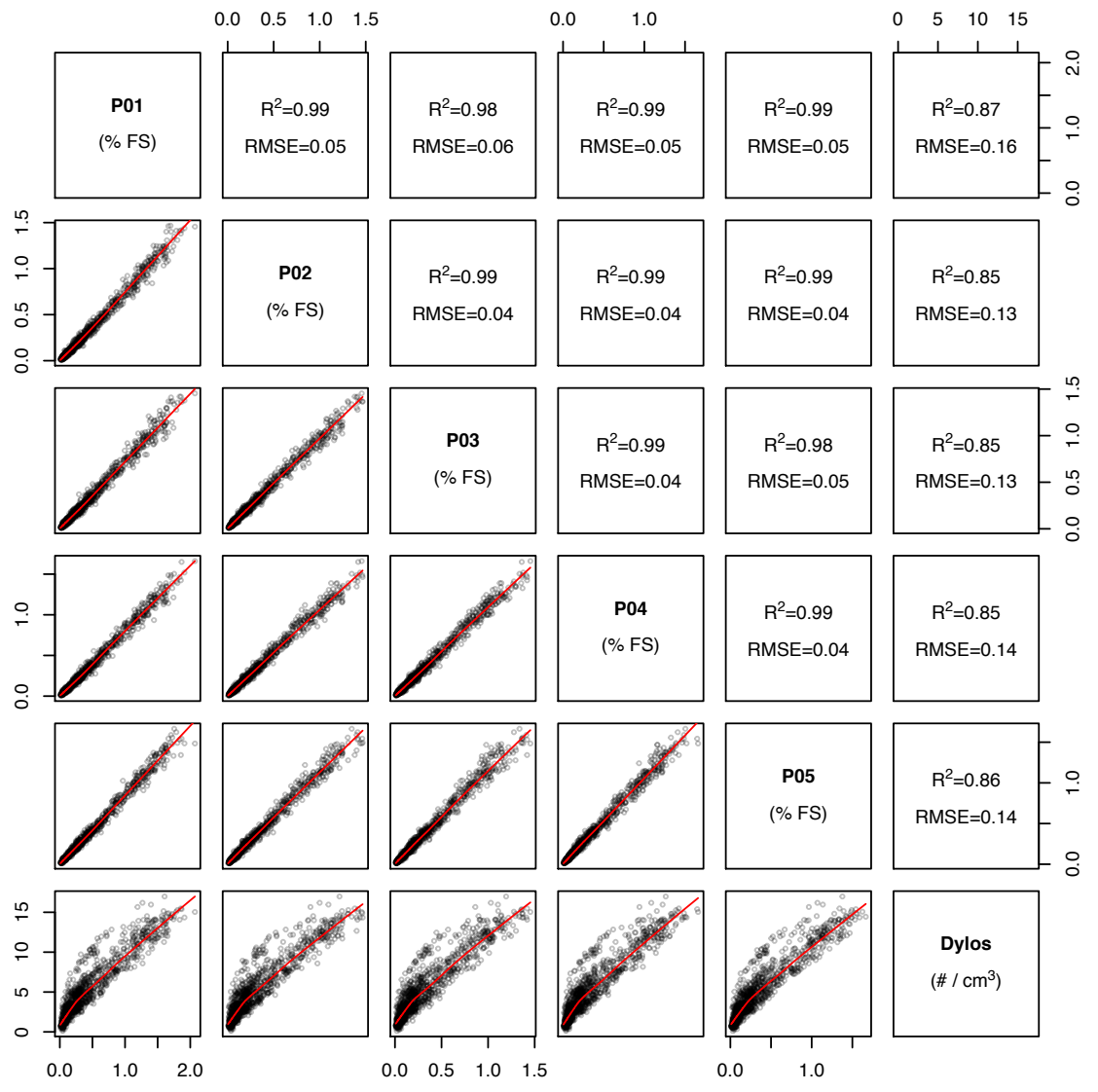

2 Figure S6. Pairwise associations (pilot study). Lower panels: $1 \mathrm{~h}$ data smoothed by loess (red 3 lines). Top panels: coefficient of determination $\left(\mathrm{R}^{2}\right)$ and root mean squared error (RMSE) for 4 linear models fit to the corresponding pairwise datasets. 
PDF of simulated concentrations

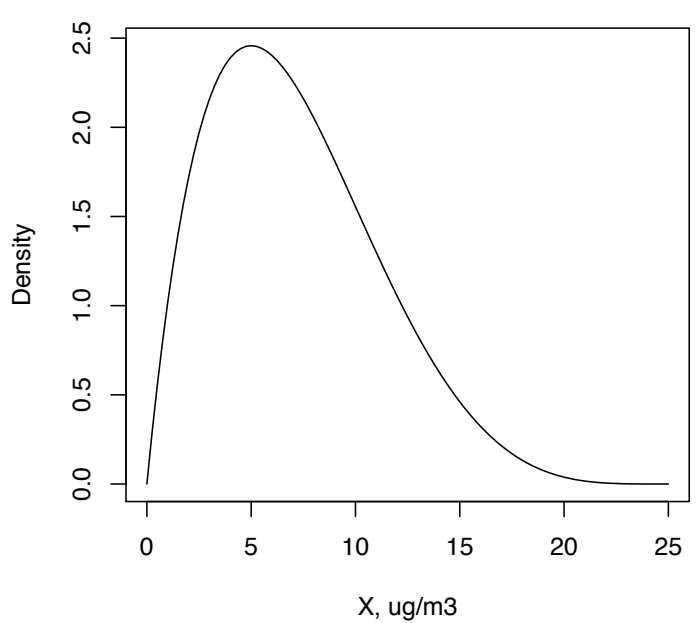

$R^{2}$ for observations $(n=190)$

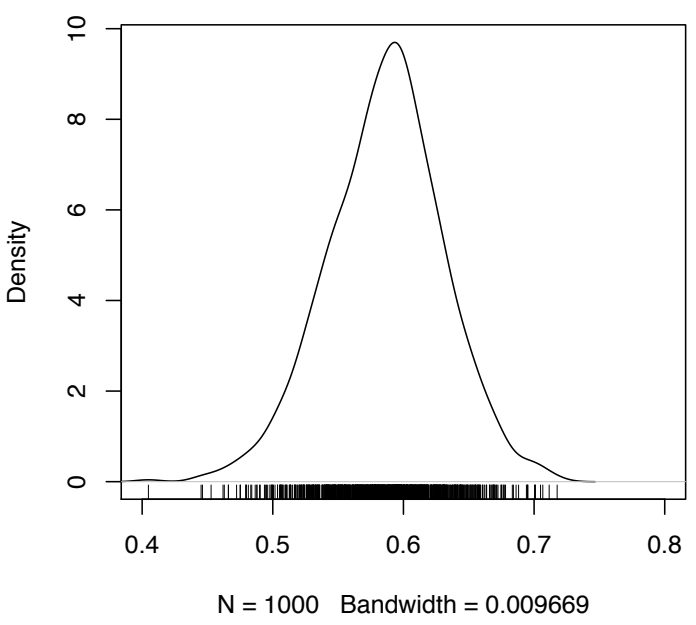

2 Figure S7. Simulation results and code. Left: scaled probability density function $\beta(2,5)$ from 3 which simulated $1 \mathrm{~h}$ concentrations were drawn. Right: Resulting distribution of $\mathrm{R}^{2}$ from 41000 trials, each having 190 paired observations. Below: simulation code (R 3.0, 5 http://www.r-project.org).

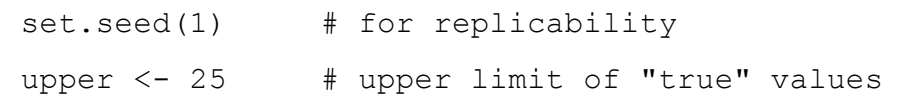

